\title{
Integrating knowledge seeking into knowledge management models and frameworks
}

\author{
Authors: \\ Francois Lottering ${ }^{1}$ \\ Archie L. Dick ${ }^{1}$ \\ Affiliations: \\ ${ }^{1}$ Department of Information \\ Science, University of \\ Pretoria, South Africa \\ Correspondence to: \\ Francois Lottering \\ Email: \\ frankie.lottering@partner. \\ bmw.co.za \\ Postal address: \\ Private Bag X20 Hatfield, \\ Pretoria 0028, South Africa \\ Dates: \\ Received: 30 Jan. 2012 \\ Accepted: 25 May 2012 \\ Published: 12 Sept. 2012 \\ How to cite this article: \\ Lottering, F. \& Dick, A.L., \\ 2012, 'Integrating knowledge \\ seeking into knowledge \\ management models and \\ frameworks', SA Journal of \\ Information Management \\ 14(1), Art. \#515, 9 pages. \\ http://dx.doi.org/10.4102/ \\ sajim.v14i1.515
}

(C) 2012. The Authors. Licensee: AOSIS OpenJournals. This work is licensed under the Creative Commons Attribution License.
Background: A striking feature of the knowledge management (KM) literature is that the standard list of KM processes either subsumes or overlooks the process of knowledge seeking. Knowledge seeking is manifestly under-theorised, making the need to address this gap in KM theory and practice clear and urgent.

Objectives: This article investigates the theoretical status of the knowledge-seeking process in extant KM models and frameworks. It also statistically describes knowledge seeking and knowledge sharing practices in a sample of South African companies. Using this data, it proposes a KM model based on knowledge seeking.

Method: Knowledge seeking is traced in a number of KM models and frameworks with a specific focus on Han Lai and Margaret Graham's adapted KM cycle model, which separates knowledge seeking from knowledge sharing. This empirical investigation used a questionnaire to examine knowledge seeking and knowledge sharing practices in a sample of South African companies.

Results: This article critiqued and elaborated on the adapted KM cycle model of Lai and Graham. It identified some of the key features of knowledge seeking practices in the workplace. It showed that knowledge seeking and sharing are human-centric actions and that seeking knowledge uses trust and loyalty as its basis. It also showed that one cannot separate knowledge seeking from knowledge sharing.

Conclusion: The knowledge seeking-based KM model elaborates on Lai and Graham's model. It provides insight into how and where people seek and share knowledge in the workplace. The article concludes that it is necessary to cement the place of knowledge seeking in KM models as well as frameworks and suggests that organisations should apply its findings to improving their knowledge management strategies.

\section{Introduction}

For some companies, knowledge management (KM) starts with specific information technology (IT) applications. Other companies leave KM to their human resources or marketing departments. However, 'intelligent' companies formulate knowledge management strategies (KMSs) to guide the development of their knowledge management capabilities (Seeley 1999).

Being the best in a highly competitive business world is no longer good enough. It is necessary to be better than the best. This means that companies can never stop improving. There are many tools and techniques businesses use to gain a competitive edge. Many of these are fads that come and go or that quickly fall away to be replaced by the next big promise to give companies the edge over their competitors. However, there is consensus that a more enduring and reliable success factor is knowledge, or as Prusak (2001:11) puts it: 'In the emerging economy, a firm's only advantage is its ability to leverage and utilise its knowledge.'

KM is not entirely new. For hundreds of years we 'knowledgeable' human beings have been doing KM, although not in the strict theoretical sense of the term. As humans, we have been telling stories around campfires and in other locales for centuries. In this sense, there has always been knowledge sharing. In the agricultural and industrial ages, fathers and mothers handed down the secrets and knowledge of their trades to their sons and daughters.

This is much the same in today's information or post-industrial age. In companies and organisations, team leaders or mentors explain the 'ins and outs' of their jobs to new employees. Cruywagen, Swart \& Gevers (2008) explain that knowledge about discoveries made thousands of years ago, and passed on to succeeding generations through storytelling, apprenticeships and in written form, has helped to promote the rise of modern industries. Sharing expertise and exchanging ideas has led to the creation of new knowledge and applying this new knowledge to common problems has resulted in countless innovations (Cruywagen et al. 2008:101). 
KM has indeed become a strategy for increasing competitiveness (Bell \& Jackson 2001). Despite this, there is still speculation that $\mathrm{KM}$ is a fad and possibly a fading endeavour (Cruywagen et al. 2008). This speculation includes concerns that models, frameworks and strategies drive KM and that they fail to consider factors like the behaviour and perspectives of those whouse the knowledge, thehistorical and cultural contexts of companies and the size of the companies. This tension between 'promoting competitiveness' and 'a passing fad' makes further investigation compelling.

Most KM models and frameworks present KM best practices but fail to address the contextual differences between organisations. As a result, KM initiatives often fail 'and fuel the fear that KM is simply just another passing fad' (Cruywagen et al. 2008:101). To account for these contextual differences, they emphasise that KM models and frameworks need to shift their focus from best practice to best-fit approaches. The two approaches use KM models and frameworks with different outlooks as their bases. The implication is that KMS strategies change according to the KM models or frameworks that companies adopt.

A significant contextual concern that best-fit approaches to KM models, frameworks and strategies raise is that they fail to recognise sufficiently all aspects of the knowledge behaviour of users. What is more striking in the KM literature is that standard lists of KM processes either subsume or overlook the processes of knowledge seeking. In other words, the processes of knowledge seeking are manifestly undertheorised in the KM literature (King, Chung \& Haney 2008; Lai \& Graham 2009). Therefore, it is necessary to address this gap in KM theory and practice clearly and urgently.

In order to address this gap, this study investigates the need to consolidate the status of the knowledge-seeking processes in KM models and frameworks. It also statistically describes knowledge seeking and knowledge sharing practices in a sample of companies. Taken together, the two components can integrate the knowledge seeking processes into a $\mathrm{KM}$ model that will enable companies to design KMSs that leverage the actual knowledge seeking practices of employees and improve best-fit approaches.

\section{Theoretical status of knowledge seeking}

The literature has already identified more than $160 \mathrm{KM}$ models and frameworks around the world. In an analysis of these models and frameworks, Heisig (2009) called for the harmonisation of the wide range of diffuse KM terms and concepts in order to standardise and consolidate them.

He discovered six $\mathrm{KM}$ processes that $\mathrm{KM}$ models and frameworks use most frequently. They are 'create', 'identify', 'share', 'acquire', 'use' and 'store'. Heisig (2009) did not explicitly identify knowledge seeking or searching as a category or as a term. However, terms like 'searching', 'locating', 'gathering' and 'sourcing' in the six main KM categories come closest to the idea of knowledge seeking.
Therefore, there is little more than a hint of knowledge seeking in Heisig's comprehensive review. This shows that it still receives inadequate attention as a process or activity or in relation to other processes like knowledge sharing.

Even the well-known and established models and frameworks do not refer to knowledge seeking. The socialisation, externalisation, combination and internalisation (SECI) model of Nonaka and Takeuchi (1995) does not deal with why, how and where users would seek and share knowledge. The emphasis in the SECI model, in the current analysis, falls too heavily on knowledge creation and does not mention knowledge seeking. Furthermore, in the Cynefin model of Snowden (2002), which adapts the SECI model, there is no sustained focus on knowledge seeking behaviour. However, recent theoretical work has begun to examine the need to integrate knowledge seeking with $\mathrm{KM}$ models and frameworks.

Sanjeev and Gee-Woo (2005) investigated the attitudes and intentions that influence people's knowledge seeking behaviour in electronic knowledge repositories. They found that knowledge seeking is as an aspect of knowledge sharing in the same way that knowledge contribution is an aspect of knowledge sharing. Hsieh (2009) conducted research on 'human centric knowledge seeking strategies', in which he identified knowledge stakeholders as external customers, internal support staffs and co-workers as bearers of tacit knowledge. Hsieh identified methods that knowledge seekers use to obtain knowledge from knowledge stakeholders. He believes that knowing who the knowledge stakeholders are and leveraging their knowledge is crucial for firms' benefit.

The work of Han Lai and Margaret Graham (2009) contains the most convincing argument for the importance of knowledge seeking in KM. They draw on the cycle model of King, Chung, and Haney (2008) to present an adapted KM cycle model that emphasises knowledge seeking. They distinguish between information seeking and knowledge seeking, as well as the differences between the knowledge seeker and the knower. After reviewing several KM models and frameworks, they introduce knowledge seeking as a new concept in KM and propose an adapted KM cycle to represent their ideas.

Lai and Graham argue that knowledge seeking is essentially a learning process and a crucial part of KM. Knowledge seeking is about people in the workplace who construct knowledge through problem solving and experiential learning.

They reviewed several ways of knowing and selected the constructivist approach as the most appropriate for knowledge seeking. Knowledge seekers construct knowledge for, and by, themselves. This happens when people encounter problems in the workplace that trigger the learning process. Learning occurs from trying to solve the problems and from experience.

This conception has closer connections with a practice-based perspective of knowledge, located within a constructivist discourse (Hislop 2009:10, 33). In this view, knowledge 
is embedded in human activity or work practices and emphasises sharing and acquisition through social interaction and through watching and doing. One can conclude that knowledge seeking in the workplace is an experiential learning process that improves the seekers' knowledge structure to solve problems or achieve goals.

Using these ideas, Lai and Graham group the KM processes of creation, acquisition and utilisation under knowledge seeking. They group transfer, sharing, storage and refinement with information management. Their model splits into two blocks: knowledge seeking and information management (see Figure 1).

\section{In this model:}

- refinement is an activity that selects, codifies or reduces knowledge to information

- storage is actually a database, a book or an object that stores this information

- transfer is actually information transfer.

However, utilisation is committed by people who have received helpful information and constructed it into their own knowledge structure by a learning process that is an act of knowing (Lai \& Graham 2009:471). Creation and acquisition, taken from the King, Chung and Haney cycle model, are added to utilisation in the knowledge-seeking block.

Lai and Graham admit that their model is illustrative and not definitive. It is still evolving and undergoing tests in the field. However, it does provide a way forward to understanding the important processes of knowledge seeking and its effect on organisational performance. They locate organisational performance in the knowledge-seeking block but fail to expand on this. Significantly, knowledge sharing is located in the information management block as a process that is not the essence of real knowledge management. These are provocative claims that Lai and Graham make. However, this study cannot assess them fully.

The KM literature reveals that scholars have not yet addressed knowledge seeking adequately. References to knowledge

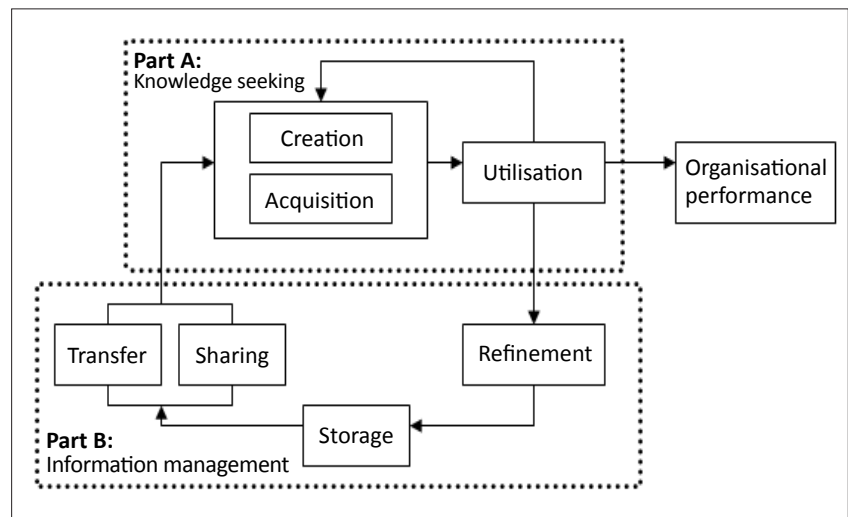

Source: Adapted from Lai, H. \& Graham, M., 2009, 'Knowledge Seeking in KM - Towards an Adapted KM Cycle', The 10th European Conference on Knowledge Management, Proceedings of ECKM 2009, Vicenza, Italy, 03-04 September.

FIGURE 1: Lai and Graham's (2009) adapted knowledge management cycle model. seeking are either absent or veiled, or they are unsatisfactory in the standard KM models and frameworks. Lai and Graham have done the most significant work to integrate knowledge seeking with KM models and frameworks and their adapted KM cycle model deserves more attention.

The empirical component of this article will describe some of the features of knowledge seeking in practice in order to critique and elaborate on Lai and Graham's adapted KM cycle model. Their separation of knowledge seeking from knowledge sharing (in the information management block) suggests that sharing is only about externalised or explicit knowledge. This raises the question of whether one can separate the two processes so sharply from each other and whether both processes cannot or do not occur together in practice.

Evaluations of their views of knowledge seeking as learning and empirical tests of their model are necessary. These assessments will require further research that this study cannot undertake here. Nevertheless, it can make a modest contribution to their model through an empirical examination of some of the features of knowledge seeking.

\section{Research design}

The research methodology combines quantitative and qualitative approaches and draws on secondary and primary sources. The target group was three South African companies.

Company $\mathrm{A}$ is a small business intelligence consultancy that focuses on high-end market products. Its projects involve planning, implementing and maintaining various business intelligence products and systems. Most projects are longterm, but there are several ad hoc short-term projects.

Company B is an IT department located within a larger company. The employees of the department are responsible for the IT infrastructure of the organisation. Their tasks range from physically installing machines to setting up users on the system and resolving IT related issues. The department requires knowledge about systems and procedures to be stored and easily communicated or shared with new employees for faster induction into the department.

Company $\mathrm{C}$ is an insurance company that deals with claims and calculates insurance rates and fees. The company is countrywide and consists of offices spread across the country. However, this study included only the Johannesburg-based branch.

Purposeful sampling is ideal for this study because it looks at the people who seek and share knowledge in the workplace. This is true of the companies the researchers selected and, because all of them engage in these processes, the researchers decided to include all employees in the target groups instead of selecting samples from each. Therefore, this is a population study of the target groups because all their employees are information-rich participants. 
The researchers collected their data from questionnaires. The questionnaires consisted of 25 closed and open-ended questions that probed the features of knowledge seeking and sharing. The questions were in four sections. Section A is about the demographic details of the participants, Section B asks questions about knowledge seeking, Section C asks questions about knowledge sharing and Section D tries to identify the knowledge-management tools that employees prefer to use. The researchers mailed the questionnaires electronically to company managers who distributed them to the participants. The managers collected and returned them to the researchers.

\section{Reliability, validity and integrity of the data}

In order to ensure the reliability, validity and integrity of the data, the researchers:

- pretested the content and format of the questionnaire with a sample

- made the questionnaire as comprehensible and explicit as possible

- protected the identity of participants to persuade them to answer freely

- triangulated the KM literature, the empirical data and the responses to the open-ended questions to assure validity

- submitted the questionnaire to the University of Pretoria's Research Ethics Committee for approval before administering it.

\section{Response rates}

The various response rates were:

- for company $\mathrm{A}$, the researchers distributed 20 questionnaires and respondents returned 13, yielding a response rate of $65 \%$

- for company $\mathrm{B}$, the researchers distributed 15 questionnaires and respondents returned 11, yielding a response rate of $73 \%$

- for company $\mathrm{C}$, the researchers distributed 33 questionnaires and respondents returned 19, yielding a response rate of $57.5 \%$.

The overall response was 43 of 68 questionnaires for the three companies, a rate of $63 \%$.

The researchers used descriptive statistics to organise, summarise and visualise the data and to describe features of knowledge seeking and searching. They analysed the openended questions by categorising words and meanings.

\section{Results}

The researchers consolidated the data from the questionnaires into a single data set instead of separate data sets for the different companies because the focus was on the processes of knowledge seeking and knowledge sharing instead of comparing them between companies. The data therefore represents knowledge seeking and sharing for all the companies instead of each individual company.

\section{Profile of respondents}

Only $14 \%$ of the respondents were women. Therefore, the data on knowledge seeking and sharing is skewed towards men. It may be useful in a future study to discover whether there are any gender differences in knowledge seeking and sharing in the workplace. Most respondents were between 21 and 40, with almost half that number in their twenties. As with gender, the differences in knowledge seeking and sharing according to age would permit further study. About half (22) of the respondents have been at their companies for more than six years. This means that there is a balanced representation of more experienced and less experienced seekers and sharers of knowledge.

\section{Knowledge seeking}

Almost all respondents said they use the Internet and/or consult colleagues when they seek knowledge to solve problems in the workplace. Sixty per cent consult knowledge repositories and books, whilst $23 \%$ use other sources. Colleagues are the greatest sources of knowledge. The high preference for consulting colleagues confirms the humancentric quality of trust relationships when seeking knowledge. People construct knowledge in their conversations about problems with their trusted colleagues. The near-rival source of the Internet suggests that employees prefer it to the KM system of data and knowledge repositories. Some respondents identified training courses, forums and subscription services as other sources of knowledge.

Sixty per cent of the respondents 'often' find the knowledge they are looking for to solve a problem or perform some or other function in their work. When the researchers correlated this data with those of previous questions, they found that colleagues successfully supply the answers employees need to solve problems in the workplace. This reinforces the continued use of colleagues as a first choice and the importance of trust when seeking knowledge. None of the respondents 'never' succeeded to find the knowledge they sought. This could indicate that knowledge seeking persists until employees find answers to their problems and confirms the 'pull' of knowledge seeking.

When the researchers asked the respondents where they seek knowledge when time is limited, the respondents' answers follow.

Table 1 shows that it is quicker to consult colleagues when seeking knowledge under the pressure of time. It also shows that knowledge seekers with time constraints or in urgent situations rely on trusted and human-centric sources. The high score for the Internet challenges consulting with colleagues and the social dimension of knowledge seeking because it is always quick and easy to use. One expects a low figure for books and knowledge repositories because they can be time consuming to sift through without the handy 'search' function.

When the researchers asked respondents why they answered as they did to the previous question, their answers follow. 
Most respondents prefer to ask colleagues when time was short. This is understandable because a colleague who already has the knowledge to answer a question or solve a problem would be able to communicate the knowledge much faster than if respondents had to search for the knowledge themselves.

This confirms Snowden's (2008) often-quoted statement that one always knows more than one says and always says more than one can write down. The data were much the same in the three companies. Each company had a higher percentage of knowledge seekers who chose to ask colleagues.

The Internet was not far behind because most people are very quick to use Google when seeking knowledge to solve workplace problems. One can describe the knowledgesearching era as the 'Google era'. However, its obvious limitation is the sheer volume of information on the Internet. It can result in more time spent searching for what one needs because of the abundance of useless information it contains. Few knowledge seekers said they would search in a knowledge repository when in a hurry because this can be time-consuming especially if it is not well-maintained or if an employee is unskilled in search techniques.

The researchers asked the respondents where they would seek knowledge in an ideal situation. Their answers follow.

Table 2 supports previous statements about the 'Google era', as $86 \%$ of employees preferred the Internet as a search tool. Even though most users previously relied on colleagues for knowledge when pressed for time, the slight drop in number may be because respondents do not want to seem ignorant or because they are too shy to ask. However, asking colleagues is part of everyday learning in the workplace and is a learning process that is '....an integral and inseparable aspect of social practice' (Lai \& Graham 2009:469).

The high number of respondents who would prefer to use knowledge repositories shows how important it is to maintain them properly. They are beneficial for knowledge seekers because they are useful for contributing, retaining and reusing knowledge.

The small number of respondents who prefer books as sources of information is not surprising because of their cumbersome nature. Seminars and conferences emerged as other sources of knowledge.

TABLE 1: Seeking knowledge with limited time.

\begin{tabular}{lcccccc}
\hline Knowledge seeker & \multicolumn{5}{c}{ Source of knowledge retrieval } \\
\cline { 2 - 7 } & Internet & Colleague & $\begin{array}{c}\text { Data or knowledge } \\
\text { repository }\end{array}$ & Book & Other \\
\hline Respondent total & 35 & 37 & 12 & 3 & 3 \\
\hline
\end{tabular}

Note: $N=43$

TABLE 2: Seeking knowledge in ideal situations.

\begin{tabular}{lcccccc}
\hline Knowledge seeker & \multicolumn{5}{c}{ Source of knowledge retrieval } \\
\cline { 2 - 7 } & Internet & Colleague & $\begin{array}{c}\text { Data or knowledge } \\
\text { repository }\end{array}$ & Book & Other \\
\hline Respondent total & 37 & 24 & 28 & 9 & 9 \\
\hline
\end{tabular}

Note: $N=43$
The data corroborates the constructivist approach to learning that Lai and Graham (2009:469) advocated. They stated that 'individuals construct knowledge through an interpretive interaction with the social world they experience'. This happens at several levels and uses several sources.

When the researchers asked respondents to explain their answers to the previous question, they indicated the main reason for the high level of confidence in the Internet is that it is fast, convenient and contains a wealth of knowledge. There was also a high response rate for knowledge repositories because it is better to have knowledge in central repositories and avoid reinventing the wheel. In addition, it is specific to the field in which they are seeking knowledge and solutions to problems. The practical implication of this is to establish these systems if they do not already exist. Colleagues, once again, are valuable sources, but respondents indicated that it depends on whether one knows who to ask for the knowledge.

\section{Seeking knowledge from within organisations}

The researchers asked respondents how often they seek knowledge from within their organisations. This is a good indication of the need to create opportunities for employees to seek, share and acquire knowledge because $35 \%$ of respondents seek knowledge a 'couple' of times a month and $25 \%$ of respondents seek knowledge once a week within their companies. Table 2 shows that $2 \%$ never seek knowledge from within their companies. Even though this figure seems negligible, it may indicate a lack of trust.

\section{Seeking knowledge from outside organisations}

The researchers also asked the respondents to indicate how often they seek knowledge from outside their organisations. The data shows that up to $33 \%$ of respondents look outside their companies for knowledge.

One can explain the reason that knowledge seekers tend to look outside for knowledge by the 'pull' force in knowledge construction that Lai and Graham described. Knowledge seekers are determined to construct their own knowledge and solve workplace problems even if it requires 'pulling' knowledge from external sources. Simply 'pushing' knowledge onto knowledge seekers, according to Lai and Graham (2009:470), 'does not necessarily lead to enhanced knowledge creation'. However, this means that it is necessary to introduce internal systems and infrastructure to make it easy to find knowledge and to provide opportunities for employees to share and seek knowledge internally.

\section{Knowledge sharing}

Sixty per cent of the respondents 'always' share knowledge with colleagues, whilst none 'never' did. This shows that most have a mindset of sharing and distributing knowledge throughout their organisations. This interesting feature of organisational culture reflects forward thinking. The biggest issue with previous mindsets have been the age-old saying 


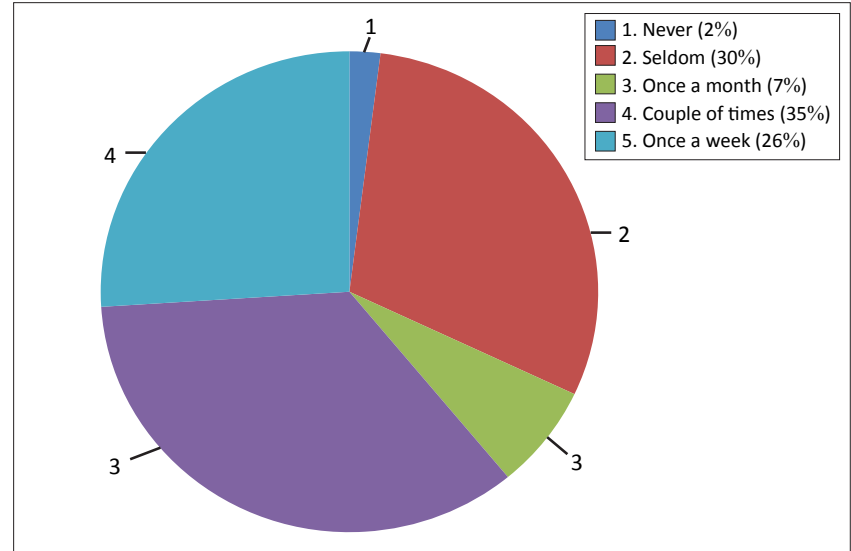

Note: $N=43$

FIGURE 2: Seeking knowledge from within organisations.

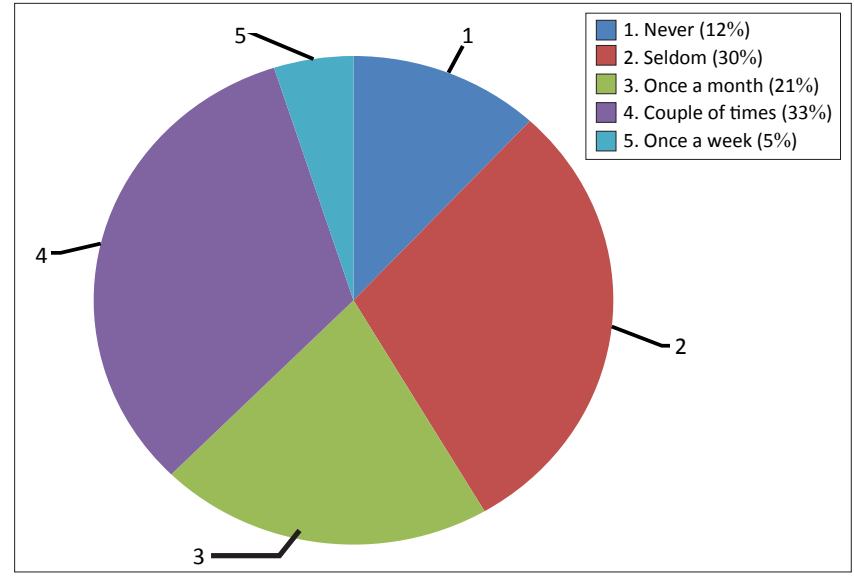

Note: $N=43$

FIGURE 3: Seeking knowledge from outside organisations.

that 'knowledge is power'. This saying applies mostly in the context of 'if I have the knowledge then I have the power and I am indispensable'. This is counter-productive to organisational learning and knowledge growth. The strength of the 'pull' of knowledge seekers increases the knowledge available to organisations.

The researchers asked respondents to indicate why they share knowledge with colleagues. Several respondents indicated that they shared knowledge for the benefit of their companies and goals. Some respondents also said that they share their knowledge because it is a requirement of their jobs. A few respondents also indicated that they shared their knowledge with colleagues to avoid re-inventing the wheel. When one compares the number that was willing to share knowledge to the number of knowledge seekers, it is clear that knowledge seekers are usually also knowledge sharers. This links the two KM process closely.

Email and face-to-face are the preferred methods of sharing knowledge. This is mainly because of the ease of face-toface sharing, as well as social interaction and trust between colleagues. If colleagues are in the same office or have easy access to others, as in open-plan designs, it is usually easier to explain concepts and share ideas person-to-person. There is often a loss of meaning and misinterpretation with emails, but they are quick and easy forms of contact and sharing. A noteworthy point is that $65 \%$ of respondents indicated that they preferred to look for knowledge in knowledge repositories. However, here only $19 \%$ shared knowledge with colleagues through knowledge repositories. This could mean that the companies do not use repositories. Alternatively, it could mean that the seekers are happy to seek knowledge in repositories but that the companies have not yet instilled the processes, of recording and sharing knowledge, into employees.

The researchers also asked respondents to indicate how they would prefer to share knowledge in an ideal situation. Most respondents indicated face-to-face as the ideal method of transferring and sharing knowledge in the workplace. This feature of knowledge sharing corroborates the social and trust-based nature of knowledge seeking and sharing.

However, knowledge repositories scored high in Company C. This suggests that they are useful in industries where there are standardised knowledge solutions to problems. Emails also featured prominently because of their ease of use as well as their recording and archiving properties.

Experiential methods featured in the category of 'other'. These respondents explained that they preferred sharing knowledge by showing colleagues how to solve problems or letting them gain experience by doing a task themselves with some supervision. This range of ideal methods for sharing knowledge supports the constructivist learning approach that Lai and Graham advocated. It involves seeking information, making sense and learning by doing, through experiences or problem solving.

\section{Knowledge repositories}

Ninety-three per cent of the respondents indicated that they would use knowledge repositories to seek knowledge to get solutions to workplace problems. This does not negate consultation with colleagues. However, it does indicate its usefulness as another source of knowledge and as an alternative learning strategy in companies.

It also corroborates data the article has already reported, where $46 \%$ of respondents indicated that they share their knowledge because their companies will benefit. The codification for retention of this knowledge is where repositories become significant. Repositories are especially useful for inducting new employees who often seek knowledge to complete tasks. Repositories also prevent the loss of many years of knowledge and experience. Therefore, they are useful for knowledge seeking and sharing.

When the researchers asked respondents why they would use knowledge repositories, most confirmed them as central points for knowledge seekers and sharers; that they bind the two processes as sources for answers to problems and as places to deposit solutions to problems for future knowledge seekers. 
All the companies understood the need to retain, share and create knowledge and respondents shared similar reasons for using knowledge repositories. They act as central points of organisational learning. The few who mentioned that repositories were not useful indicated that they could be cumbersome and time-consuming.

\section{Discussion}

The data make it possible to describe some of the main features of knowledge seeking and its relation to knowledge sharing. They also reveal some of the benefits and limitations of the Lai and Graham model.

Knowledge seekers prefer human-centric contact and social interaction because most approached colleagues when trying to solve problems. This emphasises the importance of the quality of trust in acquaintances instead of strangers and it shows a preference for personal contact over KM system facilities.

Thirty-three per cent said that they seek knowledge outside their companies. This shows a stronger sense of loyalty to internal colleagues and a reluctance to seek knowledge outside their companies. It also emphasises trust, collegiality and, importantly, the strength of the demand or pull factor in knowledge seeking that will drive people to look more widely to solve problems as well as their willingness to use other learning methods.

Most knowledge seekers share their knowledge face-to-face with colleagues. Therefore, the two processes are closely related and hard to separate in practice. They interact and overlap so that, in the course of seeking knowledge, people will also share it. One can regard this as a mutual learning situation in which both parties benefit as they seek and share knowledge. In other words, the demand or pull factor in knowledge seeking, and the supply or push factor in knowledge sharing, are deeply social in nature. This feature reveals a benefit and a shortcoming in the Lai and Graham model.

The benefit is that Lai and Graham see knowledge seeking as a different kind of process in a KM model and framework than is knowledge creation or knowledge acquisition. They assign a broader or more comprehensive scope for knowledge seeking in their model. Knowledge seeking, if it is a process, step or phase, seems to be more generic in character and can interact with all the other KM processes in special ways. However, we know too little about knowledge seeking in KM at this point to say much more than this.

The shortcoming of the Lai and Graham model is that it separates knowledge seeking from knowledge sharing. As the questionnaire data show, one cannot separate them as easily in practice. In addition, problem solving and learning is more social than situated learning theory, but they emphasise the individual as a learner and a knowledge seeker in their preferred experiential learning model.
Most respondents indicated that they would ideally use knowledge repositories to seek knowledge to find solutions to workplace problems. This indicates their usefulness as other sources of knowledge and as alternative learning strategies. Repositories are especially useful for inducting new employees who seek knowledge to complete tasks. Repositories also prevent the loss of many years of knowledge and experience and they are useful for both knowledge seeking and knowledge sharing.

Lai and Graham adopt the cognitive approach to knowledge construction and they review several approaches to learning in the workplace that favour the individual knowledge seeker. A limitation of their approach is that there are several learning theories and learning styles. In addition, there is more than one approach to knowledge construction, like cognitive constructivism and social constructivism.

Even though the argument for their choice is convincing, other approaches may be equally applicable despite their own shortcomings. In other words, there should be room for more theoretical approaches to the study of knowledge seeking in KM. Another limitation is the model's focus on people as 'knowers' or knowledge seekers. KM implies that entities, like organisations and companies, can also 'know' in the sense that people do. Therefore, companies can also seek knowledge, solve problems and learn. Future studies should investigate the most suitable approaches for collective or group learning, problem solving and 'knowing'. Therefore, the Lai and Graham model is too individualistic.

Based on these observations about the features of knowledge seeking and the benefits and limitations of the Lai and Graham model, the researchers can propose a modified knowledge seeking knowledge-based KM model.

\section{Knowledge seeking}

This is the core of the model. Although it is generic in character and, unlike knowledge creation, knowledge acquisition, knowledge seeking is a theoretical element that one can no longer overlook or assume in KM models and frameworks. One can understand knowledge seeking using the concepts of knowledge construction, learning theories,

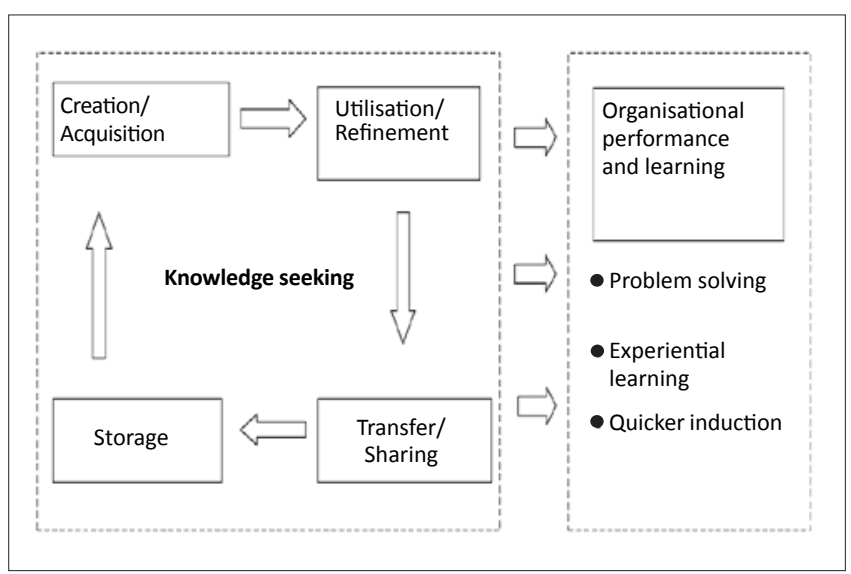

FIGURE 4: Knowledge seeking model based on knowledge management. 
learning styles and problem solving. Knowledge seeking is a generic and special kind of process that interacts with other $\mathrm{KM}$ processes in ways that still have to be investigated.

\section{Creation and acquisition}

Most knowledge seekers acquire knowledge from colleagues to solve problems. This shows that knowledge seeking is closely interrelated with knowledge creation and acquisition, and that learning from colleagues involves human-centric and trust relationships as important qualities in workplace problem solving. The practical implication of the connections is that it would be useful to establish working environments that promote social contact with colleagues and that are conducive to building trust relationships.

\section{Utilisation and refinement}

The demand or pull factor to solve problems will drive knowledge seekers to look for and use sources outside their companies. Learning continues through the utilisation and refinement processes when knowledge seekers select and use information sources outside their companies and refine them into useful knowledge to make sense of, and solve, problems. In doing so, knowledge seekers undergo experiential learning and they can share these experiences with colleagues.

\section{Transfer and sharing}

Most knowledge seekers share their knowledge socially with colleagues. The two processes are closely integrated and hard to separate in practice. When people seek knowledge, they will also share it. The practical implication is that organisations can successfully build repositories using the knowledge that knowledge seekers acquire.

\section{Storage}

Organisations need to store knowledge for reuse because they cannot afford to lose already created and acquired knowledge. One needs to look at storage from the point of view of the knowledge seeker. In other words, employees should be skilled in search techniques. They should also adopt positive attitudes to seeking the knowledge that repositories store.

\section{Organisational performance and learning}

Integrating knowledge seeking as a KM process in a KM model or framework will improve organisational performance and organisational learning in a number of ways:

- organisations will resolve problems more effectively because of special provisions in their workplaces to construct environments that accommodate alternative individual learning methods, like the oral, printed and visual styles

- recognising experiential and other learning methods as ways of solving problems will improve personal and company growth

- practical arrangements to accommodate the interrelatedness of knowledge seeking and knowledge sharing will ensure quicker induction of new personnel and smooth transitions into companies; this will reduce the time lag for new personnel to become productive.

Just as Lai and Graham's model builds on that of King, Chung and Haney (which drew from other well-known models), this proposed model advances that of Lai and Graham. Further research is necessary to flesh out this model's components in order to cement the place of the knowledge seeking process in $\mathrm{KM}$ models and frameworks.

\section{Conclusion}

Most KM models and frameworks overlook the knowledge seeking process. Despite this, knowledge seeking can enrich an understanding of $\mathrm{KM}$ and improve the chances of successfully implementing KM strategies in businesses. Studies of knowledge-seeking behaviour will improve decision-making in the workplace through a deeper understanding of how people solve problems and how they learn through experience.

Knowledge seeking occurs in companies, regardless of whether they have strategies, frameworks or designs, because people always seek knowledge to solve problems. They usually share this knowledge with colleagues. However, a deeper understanding of the process of knowledge seeking can add value to the design of a 'best-fit' KM strategy, although future studies need to investigate this.

Such a KMS will promote organisational goals better because it uses an understanding of how employees seek and share knowledge in the workplace as its basis. This understanding will improve organisational methods, tools and procedures. In a recursive approach, in which ongoing investigations produce updated insights about how knowledge seekers solve problems and apply a range of learning styles, KM and KMS will become more effective.

\section{Acknowledgements Competing interests}

The authors declare that they have no financial or personal relationship(s) that may have inappropriately influenced them when they wrote this paper.

\section{Authors' contributions}

F.B.L. (University of Pretoria) and A.L.D. (University of Pretoria) were responsible for all efforts in writing the manuscript.

\section{References}

Bell, D. \& Jackson, L., 2001, 'Knowledge management: understanding theory and developing strategy', Competitiveness Review 11(1), 1-11.

Cruywagen, M., Swart, J. \& Gevers, W., 2008, 'One Size Does Not Fit All - Towards a Typology of Knowledge-Centric Organisations', The Electronic Journal of Knowledge Management 6(2), 101-110. 
Heisig, P., 2009, 'Harmonisation of knowledge management - comparing $160 \mathrm{KM}$ frameworks around the globe', Journal of Knowledge Management 13(4), 13-41.

Hislop, D., 2009, Knowledge Management in Organisations: a critical introduction Oxford University Press, New York.

Hsieh, M., 2009, 'Human centric knowledge seeking strategies: a stakeholder perspective', Journal of Knowledge Management 13(4), 115-133. http://dx.doi. org/10.1108/13673270910971879

King, W., Chung, T. \& Haney, M., 2008, 'Knowledge Management and Organizational Learning', The International Journal of Information Science 8(2), 19-35.

Lai, H. \& Graham, M., 2009, 'Knowledge Seeking in KM - Towards an Adapted KM Cycle', The 10th European Conference on Knowledge Management, Proceedings of ECKM 2009, Vicenza, Italy, 03-04 September.

Nonaka, I. \& Takeuchi, H., 1995, The knowledge creating company: how Japanese companies create the dynamics of innovation, Oxford University Press, New York.
Prusak, L., 2001, 'Where did knowledge management come from?', IBM Systems Journal 40(4), 1002-1007. http://dx.doi.org/10.1147/sj.404.01002

Sanjeev, S. \& Gee-Woo, B., 2005, 'Factors Influencing individual's knowledge seeking behaviour in electronic knowledge repository', The 13th European Conference on Information Systems, Information System in a Rapidly Changing Economy, Proceedings of ECIS 2005, Regensburg, Germany, 26-28 May.

Seeley, C., 1999, 'Crafting a Knowledge Management Strategy. Part One - Balancing Corporate Dreams with Cultural Reality', Knowledge Management Review 11 $18-21$

Snowden, D., 2002, 'Complex acts of knowing: Paradox and Descriptive Selfawareness', Journal of Knowledge Management 6(2), 100-111. http://dx.doi. org/10.1108/13673270210424639

Snowden, D., 2008, 'Redefining knowledge', The Cognitive Edge Network, viewed 14 March 2010, from http://cognitive-edge.com/blog/entry/5576/rendering-knowledge 